\title{
Characterization of the High-Strength Mg-3Nd-0.5Zn Alloy Prepared by Thermomechanical Processing
}

\author{
Jiří Kubásek ${ }^{1} \cdot$ Drahomír Dvorský $^{1} \cdot$ Jozef Veselý $^{2} \cdot$ Peter Minárik $^{2} \cdot$ Mária Zemková $^{2} \cdot$ Dalibor Vojtěch $^{1}$
}

Received: 13 December 2017 / Revised: 26 March 2018/Published online: 29 June 2018

(C) The Chinese Society for Metals and Springer-Verlag GmbH Germany, part of Springer Nature 2018

\begin{abstract}
Magnesium alloys based on $\mathrm{Nd}$ and $\mathrm{Zn}$ are promising materials for both aviation industry and medical applications. Superior mechanical properties of these materials can be achieved by thermomechanical processing such as extrusion or rolling and by aging treatment, which can significantly strengthen the alloy. The question remains especially about the connection of texture strength created in the alloys based on the specific conditions of preparation. This work focuses on the $\mathrm{Mg}-3 \mathrm{Nd}-0.5 \mathrm{Zn}$ magnesium alloy prepared by hot extrusion of the as-cast state at two different temperatures combined with heat pre-treatment. Extrusion ratio of 16 and rate of $0.2 \mathrm{~mm} / \mathrm{s}$ at 350 and $400{ }^{\circ} \mathrm{C}$ were selected for material preparation. The structures of prepared materials were studied by scanning electron microscopy and transmission electron microscopy. The effect of microstructure on mechanical properties was evaluated. Obtained results revealed the strong effect of thermal pre-treatment on final microstructure and mechanical properties of extruded materials. The Hall-Petch relation between grain size and tensile yield strength has been suggested in this paper based on the literature review and presented data. The observed behavior strongly supports the fact that the Hall-Petch of extruded $\mathrm{Mg}-3 \mathrm{Nd}-0.5 \mathrm{Zn}$ alloys with different texture intensities cannot be clearly estimated and predicted. In addition, Hall-Petch relations presented in literature can be sufficiently obtained only for fraction of the $\mathrm{Mg}-3 \mathrm{Nd}-0.5 \mathrm{Zn}$ alloys.
\end{abstract}

Keywords Mg-Nd-Zn alloys $\cdot$ Extrusion $\cdot$ Thermal treatment $\cdot$ Microstructure $\cdot$ Mechanical properties

\section{Introduction}

Magnesium alloys are favored in aviation and automotive industry due to their low density and good mechanical properties [1]. However, the majority of evolved magnesium-based materials are characterized by poor corrosion resistance and rapid decrease in mechanical properties at higher temperatures [2]. Up to date, the best magnesium alloys are able to withstand temperatures up to $300{ }^{\circ} \mathrm{C}$ without significant loss of mechanical properties [3].

Available online at http://link.springer.com/journal/40195

Jiří Kubásek

kubasekj@vscht.cz

1 Department of Metals and Corrosion Engineering, Faculty of Chemical Technology, University of Chemistry and Technology Prague, Technická 5, 16628 Prague, Czech Republic

2 Department of Physics of Materials, Charles University, Ke Karlovu 5, 12116 Prague 2, Czech Republic
Development of magnesium alloys is interested in both improving the mechanical properties and decreasing the corrosion rate. $\mathrm{Mg}-\mathrm{Nd}-\mathrm{Zn}-(\mathrm{Zr})$ alloy system has been widely investigated due to the good combination of mechanical and corrosion properties [4], which is attributed to the presence of RE elements especially $\mathrm{Nd}$ in this case [5]. Neodymium is the most abundant rare earth element, and therefore, the overall cost of the material is not so increased as in the case of other $\mathrm{Mg}-\mathrm{RE}$ alloys. In $\mathrm{Mg}-\mathrm{Nd}$ binary alloys, mechanical properties are improved by solid solution strengthening and secondary intermetallic phases [6]. Neodymium has a maximum solubility in a solid solution of $\mathrm{Mg}$ about $3.6 \mathrm{wt} \%$ at an eutectic temperature $\left(545^{\circ} \mathrm{C}\right)$ [7]. Therefore, such alloys can be heat-treated above the temperature of solvus and subsequently precipitation strengthened [8]. The higher amount of $\mathrm{Nd}$ causes the increase in tensile yield strength (TYS) and ultimate tensile strength (UTS) for as-cast, heat-treated and aged alloy. However, the elongation decreases with the higher amount of $\mathrm{Nd}$ [9]. Neodymium is able to form few stable intermetallic compounds with magnesium. The most 
abundant phase in the as-cast state is eutectic $\mathrm{Mg}_{12} \mathrm{Nd}$ [1]. This phase usually dissolves during heat treatment. Other phases like $\mathrm{Mg}_{41} \mathrm{Nd}_{5}$ and $\mathrm{Mg}_{3} \mathrm{Nd}$, which were also reported in $\mathrm{Mg}-\mathrm{Nd}$ alloys [10-12], usually stay unchanged during heat treatment. Different precipitation processes depending on the amount of $\mathrm{Zn}$ have been reported recently.

1. The precipitation process in $\mathrm{Mg}-\mathrm{Nd}$ alloys involves: supersaturated solid solution $>$ Guinier-Preston zones $>\beta^{\prime \prime}>\beta^{\prime}>\beta_{1}>\beta[13-15]$.

2. In $\mathrm{Mg}-\mathrm{Nd}-\mathrm{Zn}$ system with $\mathrm{Zn}$ content less than $0.5 \mathrm{wt} \%$ a new precipitation sequence composed of clusters $(\mathrm{Nd}, \mathrm{Zn})>$ G.P.I $>$ G.P.II $>$ G.P. III $>\beta^{\prime}>\beta_{2}>\beta_{1}$ or $\gamma^{\prime}>\beta$ occurs [16].

3. The increased amount of $\mathrm{Zn}$ leads to the precipitation sequence with a supersaturated solid solution $>$ G.P. zones $>\gamma^{\prime \prime}>\gamma[16]$.

The third (3) precipitation sequence is even associated with the decrease in hardness [1], where the decrease in hardness is attributed to the plate precipitates, which form at the basal plane of the $\alpha-\mathrm{Mg}$ matrix [2]. In addition, with higher $\mathrm{Zn}$ content the prismatic plate precipitates are substituted with undesired basal plate precipitates [9]. Zinc is partially contained in the $\mathrm{Mg}-\mathrm{Nd}$ intermetallic phases, such as $\mathrm{Mg}_{12}(\mathrm{Zn}, \mathrm{Nd})$; however, the main contribution of zinc to the mechanical properties is related to the solid solution strengthening mechanism. TYS and UTS slightly rise with the amount of $\mathrm{Zn}$ for as-cast, heat-treated and aged samples. The elongation decreases with the higher amount of $\mathrm{Zn}$ in the alloy [17]. The best value of elongation was observed for the alloy with about $0.2 \mathrm{wt} \%$ of $\mathrm{Zn}$ [9].

$\mathrm{Mg}-3 \mathrm{Nd}-0.5 \mathrm{Zn}$ alloy is usually processed by casting and subsequently by heat treatment or extreme plastic deformation. Heat treatment is associated with solid solution strengthening and/or precipitation strengthening [18]. Maximum values of TYS and UTS for the as-cast materials of about 100 and $200 \mathrm{MPa}$, respectively, have been reported $[1,9,19,20]$. After solution treatment, the maximum observed value of TYS was similar as in the as-cast state; however, the UTS has been increased up to $220 \mathrm{MPa}$ [1, 2, 9]. Yield strength increased by solid solution strengthening was there compensated by grain coarsening. The ultimate tensile strength increase was caused by dissolution of secondary phases on grain boundaries. The huge increase in mechanical properties is attributed to the precipitation strengthening after artificial aging. Values about $160 \mathrm{MPa}$ of tensile yield strength and $300 \mathrm{MPa}$ of ultimate TYS were reported [1, 9, 18, 20-22].

Extreme plastic deformation (extrusion, hot-rolling) provides even better mechanical properties due to the refined final structure [23]. It has been observed that final structure and mechanical properties highly depend on extrusion conditions (temperature, extrusion ratio, extrusion speed). Zhang et al. [7] and Li et al. [24] found that higher extrusion temperature provides coarser grains. Tong et al. [25] found that higher extrusion ratio provides finer microstructure and higher yield strength, but in the paper of Zhang et al. [4], opposite conclusions have been postulated. Indisputably, extrusion causes a huge increase in mechanical properties. The highest values of TYS and ultimate yield strength obtained after this process were about 250 and $300 \mathrm{MPa}$, respectively [4, 14, 19, 26, 27]. The extrusion itself can be also combined with heat treatment. As-cast material can be solution treated before extrusion. Extruded products can be also artificially aged. Based on a few works [7, 14, 25-27], it seems that solution treatment before extrusion has just slightly positive effect on final mechanical properties. However, this effect is noticeably increased in combination with artificial aging after extrusion. On the contrary, the aging process after extrusion has just slight positive effect on mechanical properties when being used on material extruded from the as-cast state.

It is also very well known that magnesium alloys are inclinable to form a strong basal texture. After extrusion, the basal planes of hcp (hexagonal close-packed) are oriented in parallel to the extrusion direction [28]. This has a strong impact on the anisotropy of the compressive and TYS in the same loading direction. Rare earth elements partly suppress forming of the basal texture [29]. Li et al. [24] observed just slight ring basal texture after extrusion at $390{ }^{\circ} \mathrm{C}$ with extrusion ratio 16 ; however, they did not study the difference between compressive and tensile mechanical properties. This was studied in the work of Ma et al. [26]. They have found weakened texture in all prepared samples, which was contributed to $\mathrm{Nd}$ presence. RE texture consequently caused only low yield asymmetry of maximum $8 \%$.

Although there exist many studies about $\mathrm{Mg}-3 \mathrm{Nd}-$ $0.5 \mathrm{Zn}-\mathrm{Zr}$ alloys, the structure development after extrusion at different conditions is still the subject worthy of study. Therefore, the present paper brings the comprehensive study of the $\mathrm{Mg}-3 \mathrm{Nd}-0.5 \mathrm{Zn}$ alloy prepared by extrusion of the as-cast and the solution-treated material. The effect of processing conditions on structure state and mechanical properties is evaluated and discussed in comparison with the previous results concerning $\mathrm{Mg}-3 \mathrm{Nd}-0.5 \mathrm{Zn}-\mathrm{Zr}$ presented in the literature. Zirconium is added in many cases to the as-cast magnesium alloys but its effect is especially to refine the grain size. Extreme plastic deformation itself is the source of significant grain refinement, and therefore, $\mathrm{Zr}$ can be partially omitted in such kind of alloys. In addition, it was reported that $\mathrm{Zr}$ in both solid solution and secondary phases can negatively affect the corrosion rate [30]. $\mathrm{Mg}-\mathrm{Nd}-\mathrm{Zn}$ alloys are considered also for medical applications as a biodegradable material, where desirable corrosion resistance of magnesium-based materials is 
required $[31,32]$. Therefore, the $\mathrm{Zr}$-free $\mathrm{Mg}-3 \mathrm{Nd}-0.5 \mathrm{Zn}$ alloy was prepared in the present study.

\section{Materials and Methods}

\subsection{Preparation of Samples}

$\mathrm{Mg}-3 \mathrm{Nd}-0.5 \mathrm{Zn}$ (composition in wt\%) alloy was prepared by melting of pure $\mathrm{Mg}(99.9 \mathrm{wt} \%), \mathrm{Nd}(99.8 \mathrm{wt} \%)$ and $\mathrm{Zn}$ (99.9 wt\%) in an induction furnace under protective argon (99.996 wt\%) atmosphere. The melt was homogenized at $750{ }^{\circ} \mathrm{C}$ for $15 \mathrm{~min}$ followed by casting into a cylindrical brass mold with $50 \mathrm{~mm}$ in diameter and $150 \mathrm{~mm}$ high. Four cylindrical samples were prepared in this way. Two of them were then heat-treated at $540{ }^{\circ} \mathrm{C}$ for $16 \mathrm{~h}$ followed by quenching in water. All cylinders were extruded. Extrusion temperatures were 350 and $400{ }^{\circ} \mathrm{C}$. Extrusion ratio and extrusion speeds were 16 and $0.3 \mathrm{~mm} / \mathrm{s}$, respectively. Final extruded products were rods with $7.5 \mathrm{~mm}$ in diameter with composition of $96.9 \mathrm{wt} \% \mathrm{Mg}, 2.6 \mathrm{wt} \% \mathrm{Nd}$ and $0.5 \mathrm{wt} \% \mathrm{Zn}$. Sample designations are in Table 1.

\subsection{Microstructure}

Samples were ground on $\mathrm{SiC}$ grinding papers (P80-P4000) and subsequently polished on diamond paste. The final polishing was done on Topol 2 with fine particles of $\mathrm{Al}_{2} \mathrm{O}_{3}$. Subsequently, samples were etched in a solution containing $10 \mathrm{ml}$ of acetic acid, $4.2 \mathrm{~g}$ picric acid, $10 \mathrm{ml}$ distilled water and $70 \mathrm{ml}$ ethanol. The microstructure was studied by scanning electron microscopy (SEM, TescanVEGA3) equipped with energy dispersion spectrometry (EDS) and electron backscattered diffraction (EBSD, Oxford Instruments). For EBSD, final mechanical polishing was performed on neutral alumina suspension (OP-AN Suspension). Phase analyses were performed using X-ray diffraction (XRD, X'Pert Philips, $30 \mathrm{~mA}, 40 \mathrm{kV}, \mathrm{Cu} K_{\alpha}$ $\mathrm{X}$-ray radiation). Transmission electron microscopy (TEM, Jeol 3010) operated at an accelerating voltage of $300 \mathrm{kV}$ was used for TEM examination. TEM foils were first prepared from the samples by mechanical grinding, followed by dimpling (Gatan Dimple Grinder 656) to a thickness of $3 \mu \mathrm{m}$. Final TEM foils were obtained by subsequent precision ion polishing (Gatan PIPS 691).

\subsection{Mechanical Properties}

Compressive tests were performed on LabTest 5.250SP1$\mathrm{VM}$ at room temperature on cylindrical samples with $6 \mathrm{~mm}$ in diameter and $9 \mathrm{~mm}$ in height. Constant deformation speed of $0.001 \mathrm{~s}^{-1}$ was selected. Compressive yield strength (CYS), ultimate compressive strength (UCS) and total deformation were determined. Tensile properties were measured on the same machine at room temperature on samples with $3.5 \mathrm{~mm}$ in diameter in the constricted area and $25 \mathrm{~mm}$ in length. Constant deformation speed of $0.001 \mathrm{~s}^{-1}$ was selected. TYS, UTS and elongation were determined. Vickers hardness according to the EN ISO 6507-1 was performed at loading corresponding to $1 \mathrm{~kg}$.

\section{Results and Discussion}

\subsection{Microstructure}

Firstly, $\mathrm{Mg}-3 \mathrm{Nd}-0.5 \mathrm{Zn}$ alloys were extruded both in the as-cast state and after T4 (540/16 h) treatment. Structure of $\mathrm{Mg}-3 \mathrm{Nd}-0.5 \mathrm{Zn}$ alloy extruded at $350{ }^{\circ} \mathrm{C}$ from the as-cast state consists of the $\alpha-\mathrm{Mg}$ matrix $(0.91 \pm 0.40 \mathrm{wt} \% \mathrm{Nd}$, $0.19 \pm 0.11 \mathrm{wt} \% \mathrm{Zn}$ ) and phases rich in $\mathrm{Nd}$ arranged predominantly in rows parallel to the extrusion direction (Fig. 1a). There are also visible holes after these phases due to the fact that some phases dropped off the matrix during etching. The phases were identified as $\mathrm{Mg}_{3} \mathrm{Nd}$, $\mathrm{Mg}_{12} \mathrm{Nd}$, and $\mathrm{Mg}_{41} \mathrm{Nd}_{5}$. Zinc was observed in the structure dissolved in the $\mathrm{Mg}$-matrix and also in $\mathrm{Mg}-\mathrm{Nd}$ intermetallic binary phases, where it partly substituted Nd. TEM analysis revealed few newly precipitated $\beta$ phases (Fig. 2a, b). Huge particles inside the grains and also medium-sized particles at the grain boundaries predominantly correspond to the $\mathrm{Mg}_{12} \mathrm{Nd}$ phase $(\beta)$. In addition, rectangular or squared particles of $\beta_{1}-\mathrm{Mg}_{3} \mathrm{Nd}$ fcc phase (D03 structure, $a=0.74 \mathrm{~nm}$ ) were observed inside the grains. These phases precipitated predominantly in the areas enriched by $\mathrm{Nd}$ as a consequence of dendritic microsegregation in the as-cast state. Phases, which are precipitated at the grain boundaries, can work as effective obstruct for grain growth. Extrusion led to partial recrystallization of the material. There were regions with small newly formed equiaxed grains and also regions of

Table 1 Designation of studied materials in relation to the processing conditions

\begin{tabular}{lllrr}
\hline Label & AC+Ex350 & T4+Ex350 & AC+Ex400 & T4+Ex400 \\
\hline Process & $\begin{array}{c}\text { As-cast ingot } \\
\text { extruded at } 350{ }^{\circ} \mathrm{C}\end{array}$ & $\begin{array}{c}\text { Solution-treated ingot } \\
\text { extruded at } 350{ }^{\circ} \mathrm{C}\end{array}$ & $\begin{array}{c}\text { As-cast ingot } \\
\text { extruded at } 400{ }^{\circ} \mathrm{C}\end{array}$ & $\begin{array}{r}\text { Solution-treated ingot } \\
\text { extruded at } 400{ }^{\circ} \mathrm{C}\end{array}$ \\
\hline
\end{tabular}



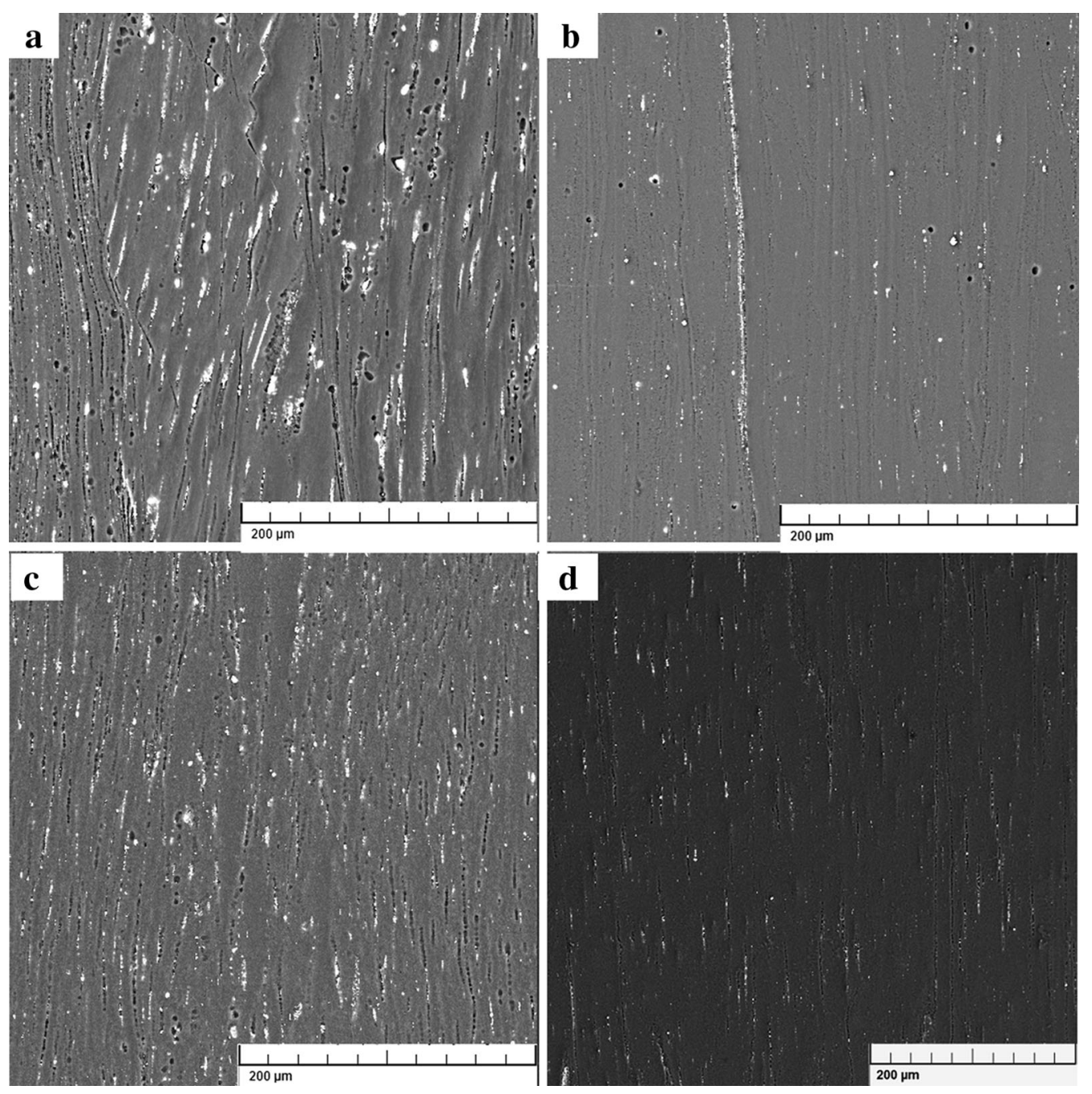

Fig. 1 Microstructure of Mg-3Nd-0.5Zn alloys (SEM): a AC+Ex350, b T4+Ex350, c AC+Ex400, d T4+Ex400. Light particles and dark areas correspond to intermetallic phases especially $\mathrm{Mg} 41 \mathrm{Nd} 5$ and primary $\alpha-\mathrm{Mg}$, respectively

elongated strongly deformed grains with subgrain structure at some areas (Fig. 4a). Similar regions have been already observed in products extruded at temperatures from 250 to $350{ }^{\circ} \mathrm{C}[4,23,27,33,34]$.

The solid solution of the samples prepared by extrusion at $350{ }^{\circ} \mathrm{C}$ of thermally treated (T4) material contained $2.31 \pm 0.30 \mathrm{wt} \%$ of $\mathrm{Nd}$ and $0.42 \pm 0.11 \mathrm{wt} \%$ of $\mathrm{Zn}$, which are significantly higher values compared to the material extruded without previous thermal treatment. In addition, the concentration of alloying elements in the solid solution was very homogenous. This is caused firstly by removal of dendritic microsegregation and secondly by the dissolution of $\mathrm{Mg}_{12} \mathrm{Nd}$ eutectic phase during heat treatment, although some more thermally stable intermetallic phases, such as $\mathrm{Mg}_{41} \mathrm{Nd}_{5}$ and $\mathrm{Mg}_{3} \mathrm{Nd}$ remained in the structure (Fig. 1b). During extrusion, strong precipitation took place, as can be seen from Fig. 2c. Precipitates were characterized predominantly by a rectangular shape and the size below $100 \mathrm{~nm}$. These phases were determined as $\beta_{1}-\mathrm{Mg}_{3} \mathrm{Nd}$ fcc phase. The high tendency for precipitation is connected with the higher content of $\mathrm{Nd}$ in a solid solution of $\alpha-\mathrm{Mg}$ as a consequence of solution annealing before extrusion.

Other ingots were extruded at $400{ }^{\circ} \mathrm{C}$. The $\mathrm{Mg}-3 \mathrm{Nd}-$ $0.5 \mathrm{Zn}$ alloy prepared by extrusion at $400{ }^{\circ} \mathrm{C}$ from the ascast material contained a slightly higher amount of alloying elements in the solid solution $(1.12 \pm 0.27 \mathrm{wt} \% \mathrm{Nd}$, $0.24 \pm 0.18 \mathrm{wt} \% \mathrm{Zn}$ ) than material prepared by extrusion at $350{ }^{\circ} \mathrm{C}$. This is caused by partial homogenization of the solid solution during extrusion process at a higher temperature, which makes diffusion in material easier. Occurring intermetallic phases tend to be smaller and more homogeneously dispersed in the structure, but the rows parallel to the extrusion direction still exist here (Fig. 1c). Also different kinds of precipitates appear in the structure (Fig. 3a). Small globular particles with about 100-300 $\mu \mathrm{m}$ in diameter correspond to the $\beta_{1}-\mathrm{Mg}_{3} \mathrm{Nd}$ phase. In addition, huge particles were identified as $\mathrm{Mg}_{41} \mathrm{Nd}_{5}$ (tetragonal structure with $a=1.47, c=1.04 \mathrm{~nm}$ ). 

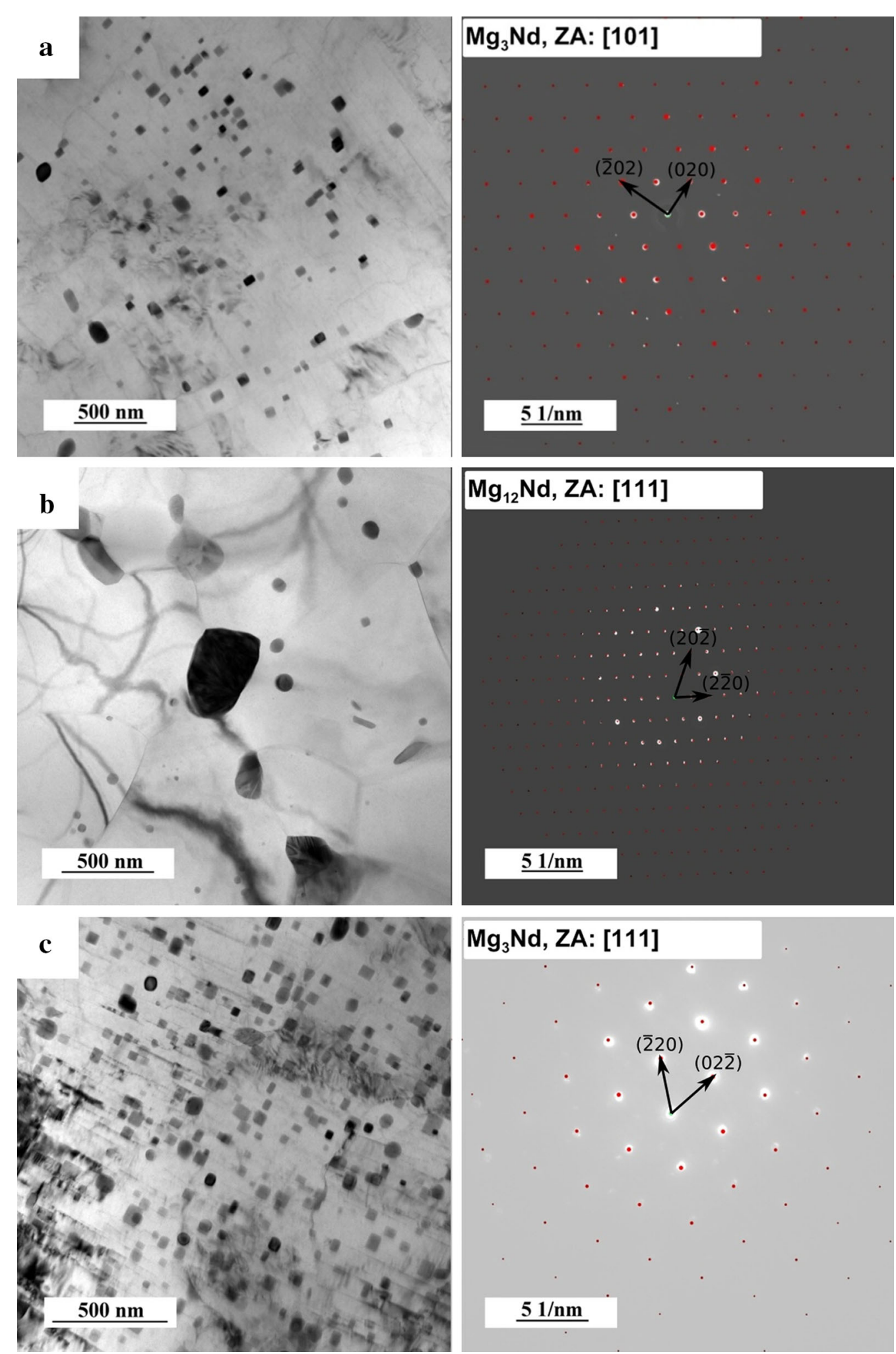

Fig. 2 Intermetallic phases observed in extruded Mg-3Nd-0.5Zn (TEM): a, b AC+Ex350, c T4+Ex350. Individual figures illustrate the presence of specific phases with their corresponding SAED patterns. ZA designation means zone axis

In the solid solution of $\mathrm{Mg}-3 \mathrm{Nd}-0.5 \mathrm{Zn}$ alloy processed by extrusion at $400{ }^{\circ} \mathrm{C}$ after $\mathrm{T} 4$ heat treatment, the concentration of $\mathrm{Nd}$ and $\mathrm{Zn}$ reached $2.46 \pm 0.59 \mathrm{wt} \%$ and
$0.59 \pm 0.14 \mathrm{wt} \%$, respectively, which are the highest values obtained among all studied samples. Concurrently, this material contained the lowest amount of visible residual 

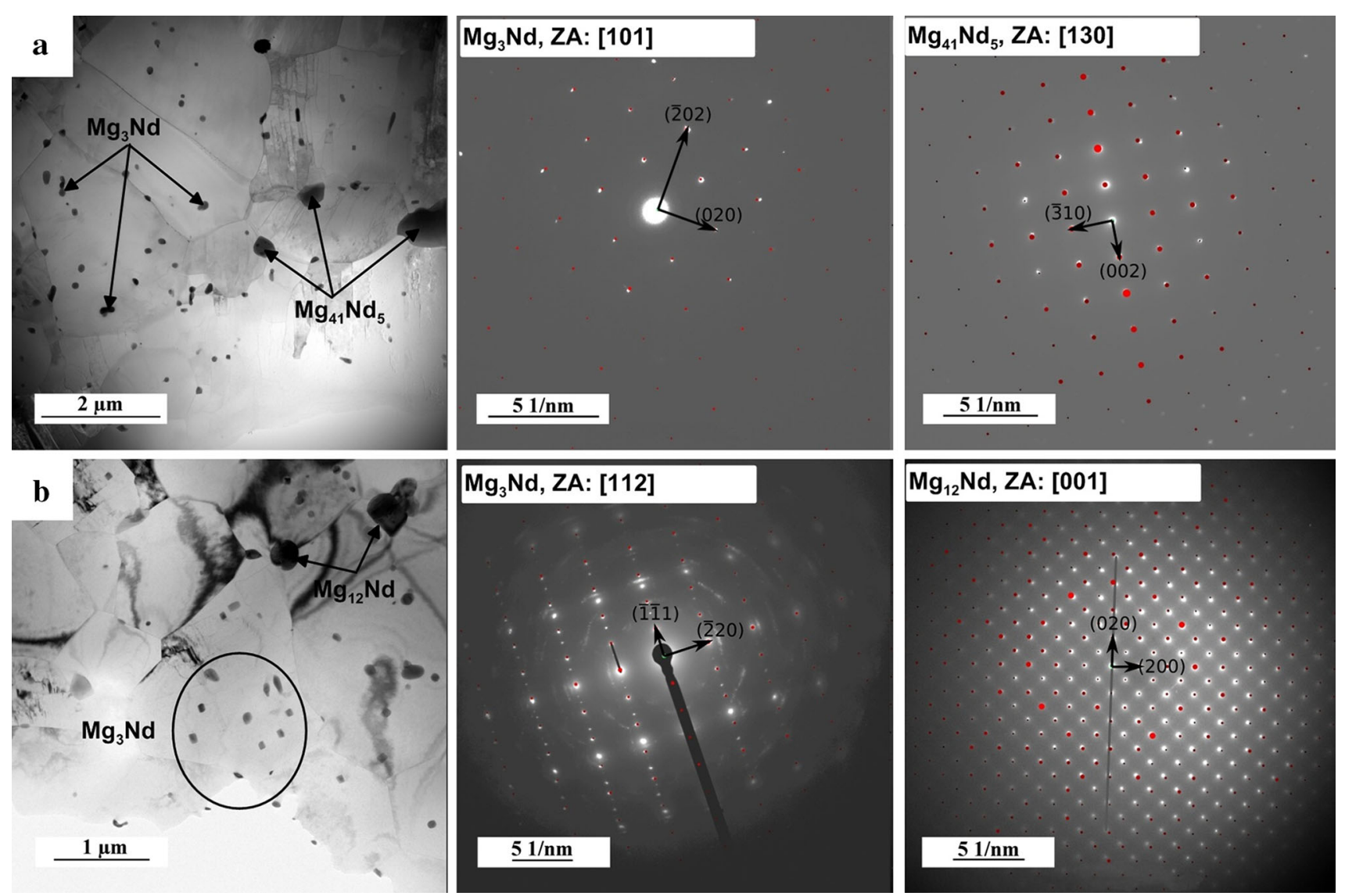

Fig. 3 Intermetallic phases observed in extruded Mg-3Nd-0.5Zn (TEM): a AC+Ex400, b T4+Ex400. Individual figures illustrate the presence of specific phases with their corresponding SAED patterns. ZA designation means zone axis

phases in the structure (Fig. 1d). Extrusion process caused strong precipitation (Fig. 3b). The amount of predominantly globular precipitates was significantly lower compared to the extrusion of as-cast state at $400{ }^{\circ} \mathrm{C}$. Instead of, rectangular particles of $\mathrm{Mg}_{3} \mathrm{Nd}$ fcc phase (D03 structure, $a=0.74 \mathrm{~nm}$ ) dominated in the structure. Huge particles with about $500-1000 \mathrm{~nm}$ in size were documented as $\mathrm{Mg}_{12} \mathrm{Nd}$ (tetragonal structure) $a=1.03 \mathrm{~nm}, c=0.59 \mathrm{~nm}$ ). Observed precipitates were dispersed both at the boundaries of recrystallized grains and inside these grains. At higher temperatures, diffusion of $\mathrm{Nd}$ or $\mathrm{Zn}$ in magnesium matrix is faster and new precipitates are coarsened more easily. The same effect is also responsible for the lower density of them in Mg matrix.

The grain size of all prepared materials was determined from the EBSD analysis, which is displayed in Figs. 4 and 5. It should be mentioned that EBSD maps are displayed here only as an illustration of the structure. Based on EBSD maps, grain size distribution curves without the elongated strongly deformed grains were evaluated (Fig. 6). There is almost no dependence of recrystallized grain size on sample preparation method. The average grain size of all materials was about $2 \mu \mathrm{m}$. Strong variance is observed in the amount of unrecrystallized elongated grains, which has a direct effect on observed texture strength in materials. White lines in strongly deformed grains represent subgrain boundaries with misorientation less than $10^{\circ}$. Inverse pole figures (IPF) for all samples are displayed in Figs. 4 and 5.

Based on the IPF maps and measured random intensity, all prepared alloys contained basal textures with basal planes oriented parallel to the extrusion direction, but the strength of the textures was different. Materials prepared by extrusion of T4-treated states were characterized by the strongest texture (random intensity 15) and largest unrecrystallized zones. On the contrary, materials prepared from the as-cast states contained the weakest texture (random intensity 5-8) and lower amount of unrecrystallized zones. Therefore, heat pre-treatment (T4) and lower extrusion temperature tend to form stronger textures. The as-cast states contained a high amount of eutectic phases which can be nuclei for new recrystallized grains. The amount of such phases is decreased after T4 treatment, and the driving force for nucleation of new grains is decreased during extrusion. Suppression of basal texture and occurrence of "rare earth" texture is sometimes connected with the presence of RE elements in the solid solution of $\mathrm{Mg}$. 


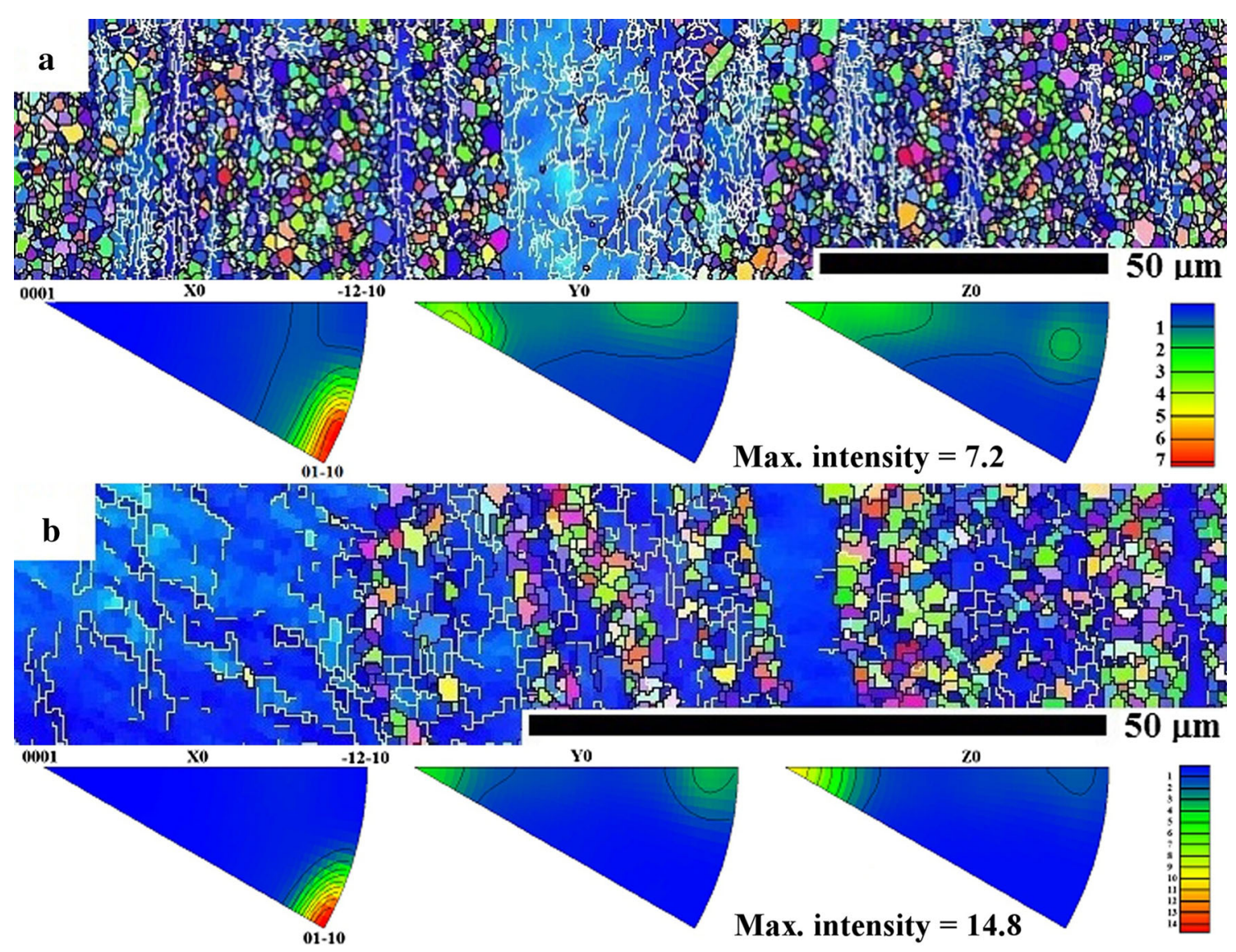

Fig. 4 EBSD maps and inverse pole figures of studied Mg-3Nd-0.5Zn alloy: a AC+Ex350, b T4+Ex350. White lines in EBSD maps represent low-angle grain boundaries characterized by angle up to $15^{\circ}$. X0 corresponds to the direction of extrusion. Inverse pole figures reflect continuous orientation distribution with contour levels showing the strength of the texture as the number of times random occurrence

Rare earth texture peak appears at approximately $\langle 11 \overline{2} 1\rangle$ parallel to the extrusion direction [35]. This phenomenon was slightly observed only in the case of AC+Ex400. However, both T4-treated materials contained significantly higher content of $\mathrm{Nd}$ in solid solution and no texture weakening has been observed; instead, there was the opposite effect. Also, quite strong precipitation, especially in the case of $\mathrm{T} 4$-treated $\mathrm{Mg}-3 \mathrm{Nd}-0.5 \mathrm{Zn}$ extruded at $350{ }^{\circ} \mathrm{C}$, seems not to have any significant effect on recrystallization and related texture strength.

\subsection{Mechanical Properties}

Vickers hardness, compressive and tensile properties were measured for all conditions. Obtained results are summarized in Table 2 and Fig. 7. The highest value of Vickers hardness was determined for the T4-treated sample subsequently extruded at $350{ }^{\circ} \mathrm{C}$. Such behavior clearly demonstrates the highest amount of precipitates $\left(\beta_{1}\right)$ in the structure (Fig. 2c) and also deformation straightened material because of huge deformed areas without recrystallization in the structure. The slightly higher hardness of the sample prepared by extrusion of the as-cast state at $350{ }^{\circ} \mathrm{C}$ compared to the extrusion at $400{ }^{\circ} \mathrm{C}$ is attributed to the higher content of deformed areas, and therefore, also stronger texture (Figs. 4 and 5). Extruded specimens, which were predominantly heat-treated by $\mathrm{T} 4$, are characterized by similar values of Vickers hardness. Globally the main contribution to the strengthening of prepared materials is caused by intermetallic phases and solid solution strengthening in the as-cast and subsequently extruded samples and by precipitation strengthening, strengthening by texture and solid solution strengthening in the case of T4-treated and extruded alloys. The effect of grain size of recrystallized regions is similar for all prepared materials (Fig. 6). From Table 2, it is evident strong effect of extrusion temperature on the mechanical properties. Lower extrusion temperature leads to higher yield strength and ultimate strength. The same conclusions were reported by Zhang et al. [7]. During extrusion at a lower temperature, the driving force for recrystallization is lower and large fraction of deformed unrecrystallized grains is obtained in the structure (Fig. 4). Heat pre-treatment (T4) before extrusion has no significant effect on compressive 


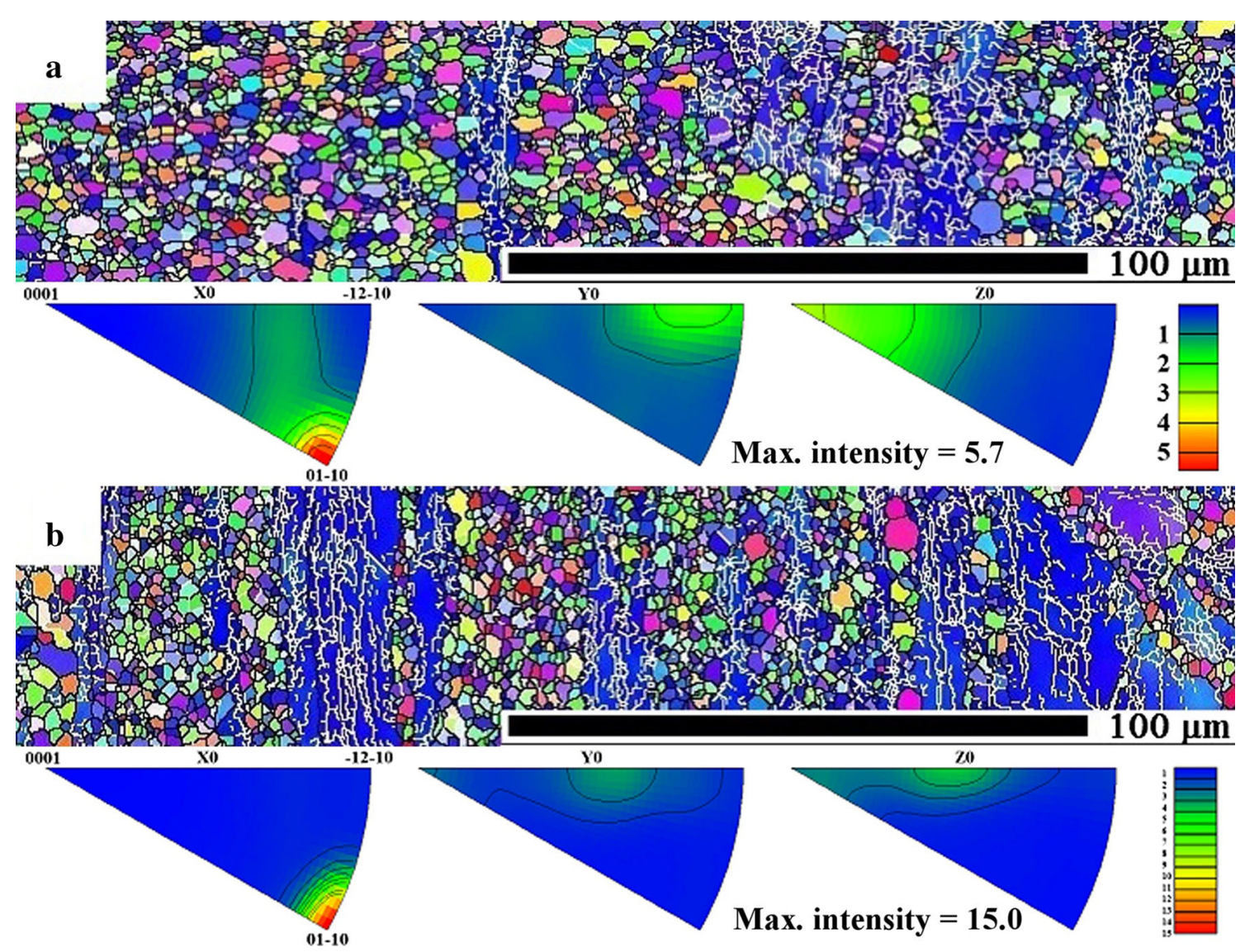

Fig. 5 EBSD maps and inverse pole figures of studied Mg-3Nd-0.5Zn alloy: a AC+Ex400, b T4+Ex400. White lines in EBSD maps represent low-angle grain boundaries characterized by angle up to $15^{\circ}$. X0 corresponds to the direction of extrusion. Inverse pole figures reflect continuous orientation distribution with contour levels showing the strength of the texture as the number of times random occurrence

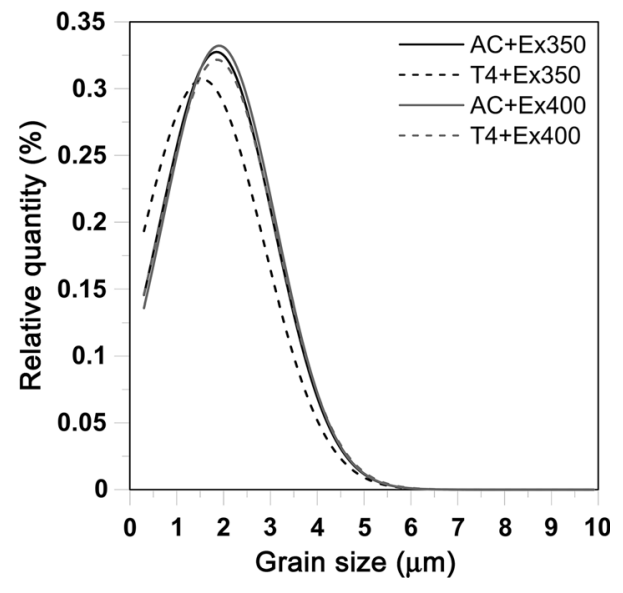

Fig. 6 Distribution of grain size in $\mathrm{Mg}-3 \mathrm{Nd}-0.5 \mathrm{Zn}$ alloy processed by extrusion at different conditions

properties; however, the tensile properties are highly affected. This might be caused by contradictory effects of solid solution strengthening, which increase CYS in the case of T4 state and texture effect, which decrease CYS in the case of $\mathrm{T} 4$ state. On the contrary, both these factors (solid solution strengthening and texture effect) increase TYS evaluated from tensile tests. Both T4-treated samples subsequently extruded at 350 and $400{ }^{\circ} \mathrm{C}$ are characterized by higher values of TYS compared to the extruded as-cast states. Due to the fact that T4 treatment before extrusion leads to the higher content of alloying elements in $\alpha-\mathrm{Mg}$ solid solution, the effect of solid solution strengthening is stronger for pre-treated and extruded materials. This explanation is supported by differences in atomic radius of $\mathrm{Mg}(0.160 \mathrm{~nm})$ and $\mathrm{Nd}(0.180 \mathrm{~nm})$. But indisputably, huge differences in mechanical properties were also affected by observed texture. This effect is clearly seen from the observed anisotropy of TYS and CYS (Table 2) because in both cases the stress was performed along the extrusion direction in both cases.

Hexagonal structures are difficult to plastically deform at room temperature due to the low amount of slipping planes. However, they are able to deform by twinning mechanism if they are appropriately oriented. The twinning mechanism requires in many cases much less energy than slip in secondary slip systems, but these differences are strongly affected by the orientation of grains toward the 
Table 2 Mechanical properties of studied materials

\begin{tabular}{llllllll}
\hline Sample & CYS $(\mathrm{MPa})$ & UCS $(\mathrm{MPa})$ & $D(\%)$ & TYS $(\mathrm{MPa})$ & UTS $(\mathrm{MPa})$ & $E(\%)$ & HV1 \\
\hline AC+Ex350 & $224 \pm 6$ & $450 \pm 11$ & $14.8 \pm 0.5$ & $337 \pm 6$ & $338 \pm 6$ & $0.5 \pm 0.2$ & $64.1 \pm 1.8$ \\
T4+Ex350 & $225 \pm 1$ & $477 \pm 18$ & $13.2 \pm 0.3$ & $384 \pm 4$ & $385 \pm 3$ & $2.8 \pm 0.2$ & $67.6 \pm 1.9$ \\
AC+Ex400 & $174 \pm 5$ & $423 \pm 12$ & $12.7 \pm 0.4$ & $251 \pm 6$ & $271 \pm 8$ & $5.9 \pm 1.0$ & $61.1 \pm 2.3$ \\
T4+Ex400 & $172 \pm 2$ & $424 \pm 13$ & $11.8 \pm 0.4$ & $312 \pm 9$ & $321 \pm 11$ & $2.7 \pm 0.7$ & $61.3 \pm 2.6$ \\
\hline
\end{tabular}

CYS compressive yield strength, UCS ultimate compressive strength, $D$ relative deformation in compression, TYS tensile yield strength, UTS ultimate tensile strength, $E$ elongation, $H V 1$ Vickers Hardness

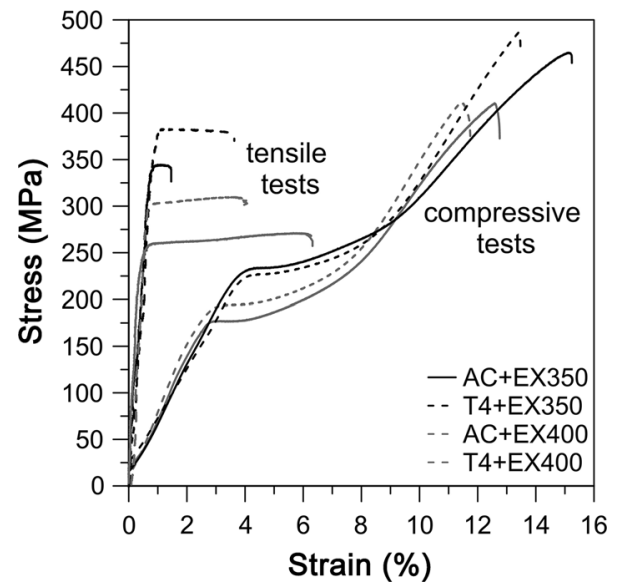

Fig. 7 Tensile (dash line) and compressive (solid line) stress-strain curves obtained for $\mathrm{Mg}-3 \mathrm{Nd}-0.5 \mathrm{Zn}$ alloy at room temperature and a strain rate of $0.001 \mathrm{~s}^{-1}$

direction of loading [36]. During extrusion grains preferably orient their basal planes parallel with the extrusion direction. Such grains are unfavorably oriented for twinning mechanism and also slip in the basal plane when the tensile force is parallel with extrusion direction (as was performed in this work) [35]. This means that the stronger the texture is the higher tensile yield strength is obtained, because basic deformation mechanisms are limited and the activation of prismatic or pyramidal slip requires more energy. The consequences are clearly evident on the values of the mechanical properties of T4+Ex350 and $\mathrm{AC}+\mathrm{Ex} 400$ states with the strongest and weakest texture, respectively (Figs. $4 \mathrm{~b}$ and 5a).

The difference between TYS and CYS is the lowest (80 MPa) for the AC+Ex400 and contrary reach almost $150 \mathrm{MPa}$ for the T4+Ex350 with the strongest texture. In the case of compressive tests with the loading axis parallel to the extrusion direction, grains are favorably oriented for tensile twinning [37]. This significantly decreases CYS and subsequently cause strong work hardening observed on the compressive curves (Fig. 7). The twinning mechanism requires in this case low energy [36], and therefore, it might be a main limiting factor for the value of compressive yield strength.

Sample with the lowest tensile and compressive strengths (AC-Ex400) reached the best value of elongation. This is due to the existence of weaker texture and smaller fraction of unrecrystallized zones (Fig. 5a) compared to other studied materials. On the contrary, the worst elongation of material $\mathrm{AC}+\mathrm{Ex} 350$ is contributed predominantly to the occurrence of many coarse intermetallic phases that cause the brittleness (Fig. 1a).

As has already been mentioned in the introduction part, $\mathrm{Mg}-\mathrm{Nd}-\mathrm{Zn}$ alloys containing about $3 \mathrm{wt} \%$ of $\mathrm{Nd}$ and 0.5 wt $\%$ of $\mathrm{Zn}$ have been the subject of different studies. Although there exist a relatively wide range of papers, Hall-Petch relation was postulated rarely. In Fig. 8, the overview of measured tensile yield strengths in connection with postulated grain size $[1,4,9,14,18-21,26,38,39]$ is displayed. To our best knowledge, Hall-Petch relation was determined only in the case of solution-treated or artificially aged alloys by $\mathrm{Li}$ et al. [21]. Those relations are represented by two slopes (dark blue line) shown in Fig. 8, and they are partially different from slopes mentioned in

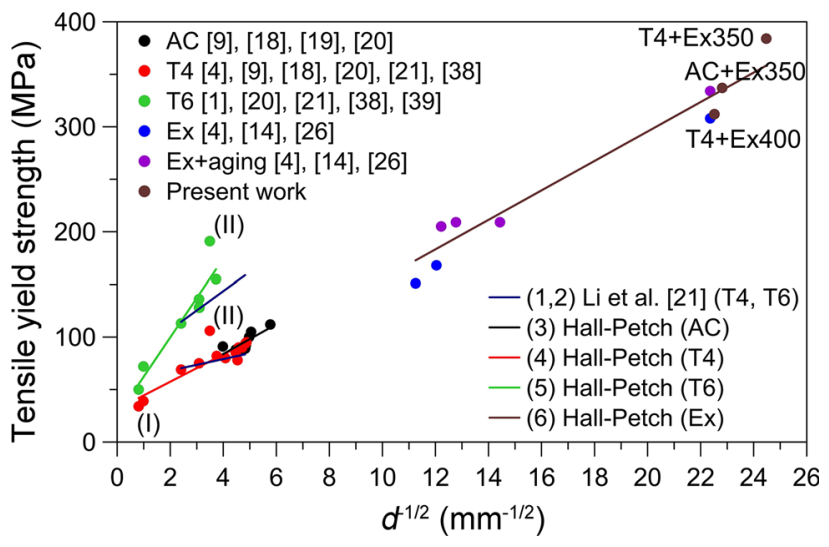

Fig. 8 Dependence of tensile yield strength on inverse square root of average grain size (Hall-Petch relation) for $\mathrm{Mg}-3 \mathrm{Nd}-0.5 \mathrm{Zn}$ alloys $[1,4,9,14,18-21,26,38,39] . \mathrm{AC}=$ as-cast; $\mathrm{T} 4=540^{\circ} \mathrm{C} /$ $10 \mathrm{~h}+$ water quenching; T6 $=\mathrm{T} 4+200{ }^{\circ} \mathrm{C} / 14 \mathrm{~h} ; \mathrm{Ex}=\mathrm{AC} / \mathrm{T} 4+$ Extrusion $\left(\mathrm{T}=300^{\circ} \mathrm{C}, 320^{\circ} \mathrm{C}\right)$, ER (extrusion ratio) $=8,9,25$; Ex+aging $=$ Extrusion $+200{ }^{\circ} \mathrm{C} / 8 \mathrm{~h}$ 
literature references listed above (solid line). From Fig. 8, it is clearly seen that measured tensile yield strengths for the extruded $\mathrm{Mg}-3 \mathrm{Nd}-0.5 \mathrm{Zn}$ alloy in combination with different treatments vary quite significantly also for materials characterized by similar grain size. Therefore, it is quite difficult to postulate proper Hall-Petch relation. However, if we consider all presented data for extruded materials, the equation can be estimated in the range of grain size 2-8 $\mu \mathrm{m}$ (Eq. (6)). The higher deviations of selected points from the curve are related to the differences in texture strength and a fraction of non-recrystallized deformed areas in the extruded alloys. The steepest increase in mechanical properties with grain size is observed for as-cast materials worked by $\mathrm{T} 6$ treatment. The increase in TYS with the decrease in grain size is less significant for as-cast and T4-treated states of $\mathrm{Mg}-3 \mathrm{Nd}-$ $0.5 \mathrm{Zn}$.

Extruded samples are characterized by significantly lower grain size. Displacement of the first 2 red dots (Fig. 8 points designation I) of T4 state may be due to no or small content of $\mathrm{Zr}$ in alloys. Therefore, very large grains with no $\mathrm{Zr}$ phases are present in the structure. The highest value of yield strength of T4 and T6 material (Fig. 8 points designated by II) may be due to the higher content of $\mathrm{Zn}$ and partially different heat treatment $\left(\mathrm{T} 4=525{ }^{\circ} \mathrm{C} / 14 \mathrm{~h}\right.$; $\mathrm{T} 6=200{ }^{\circ} \mathrm{C} / 10 \mathrm{~h}$ ). Results obtained in this work are presented by brown dots in Fig. 8. The highest TYS of the $\mathrm{T} 4+\mathrm{Ex} 350$ material was contributed to slightly finer grains and mainly to the high amount of precipitates (Fig. 2c) and strong texture (Fig. 4b). On the other hand material, $\mathrm{AC}+\mathrm{Ex} 400$ was characterized by the weakest texture intensity and the highest fraction of recrystallized grains, which together decrease final TYS.

Based on all presented data, $\mathrm{Mg}-3 \mathrm{Nd}-0.5 \mathrm{Zn}$ alloy worked by $\mathrm{T} 4$ and subsequently extruded at $350{ }^{\circ} \mathrm{C}$ offer the best combination of TYS about $370 \mathrm{MPa}$ with still acceptable elongation about $3 \%$. The TYS of $370 \mathrm{MPa}$ is the highest value obtained for classically extruded $\mathrm{Mg}-$ $3 \mathrm{Nd}-0.5 \mathrm{Zn}$ alloys and in the present case without the addition of $\mathrm{Zr}$. Although this material is characterized by the highest anisotropy of TYS and CYS, the CYS of $225 \mathrm{MPa}$ is still acceptable for many applications.

Hall-Petch relations had been postulated by $\mathrm{Li}$ et al. [21].

T4: $\sigma_{0.2}=57.1+5.4 d^{-0.5}$,
T6: $\sigma_{0.2}=70.3+18.3 d^{-0.5}$.

In present paper, Hall-Petch relations were summarized from the enlisted literature.

AC: $\sigma_{0.2}=27.3+14.2 d^{-0.5}$,
$\mathrm{T} 4: \sigma_{0.2}=45.8+9.2 d^{-0.5}$,

T6: $\sigma_{0.2}=31.5+32.6 d^{-0.5}$.

Hall-Petch relation for extruded alloys according to the presented results and literature references is described by Eq. (6); however, the presented form should be considered as indicative due to the deviation of some points from presented dependence. This is connected with the dependency of mechanical properties not only on grain size but also other variables such as texture strength, precipitation and deformation strengthening.

Ex: $\sigma_{0.2}=5.8+13.8 d^{-0.5}$.

\section{Conclusion}

As-cast and thermally treated (540/16 h) magnesium alloys designated as $\mathrm{Mg}-3 \mathrm{Nd}-0.5 \mathrm{Zn}$ were prepared by extrusion at two different temperatures 350 and $400{ }^{\circ} \mathrm{C}$. Extrusion temperature or heat treatment prior to extrusion had no effect on the final grain size of materials; however, it significantly affected the volume fraction of residual deformed areas of unrecrystallized grains and texture of the material. Heat treatment and subsequent extrusion at a lower temperature $\left(350{ }^{\circ} \mathrm{C}\right)$ led to the formation of stronger fiber texture. Increased extrusion temperature $400{ }^{\circ} \mathrm{C}$ in combination with thermal pre-treatment caused partially the $\mathrm{Mg}_{41} \mathrm{Nd}_{5}$ phase precipitation, which is not generally observed in extruded $\mathrm{Mg}-3 \mathrm{Nd}-0.5 \mathrm{Zn}$ alloys. In other cases, $\beta_{1}-\mathrm{Mg}_{3} \mathrm{Nd}$ and $\mathrm{Mg}_{12} \mathrm{Nd}$ precipitates dominated in the structure. Really promising value of TYS (384 MPa) in combination with relatively good elongation $(3 \%)$ was achieved for material $\mathrm{Mg}-3 \mathrm{Nd}-0.5 \mathrm{Zn}$ prepared by heat treatment, and subsequent extrusion at $350{ }^{\circ} \mathrm{C}$. Hall-Petch relations was determined from the combination of literature sources and presented measurements.

Acknowledgements This work was financially supported by the project Advanced magnesium alloys with tailored corrosion, biological and mechanical properties (No. GA16-08963S).

\section{References}

[1] D. Wu, R.S. Chen, W. Ke, Mater. Des. 58, 324 (2014)

[2] J. Yang, L.D. Wang, L.M. Wang, H.J. Zhang, J. Alloys Compd. 459, 274 (2008)

[3] T. Rzychoń, A. Kielbus, J. Achiev. Mater. Manuf. Eng. 21, 31 (2007)

[4] X.B. Zhang, G.Y. Yuan, J.L. Niu, P.H. Fu, W.J. Ding, J. Mech. Behav. Biomed. Mater. 9, 153 (2012)

[5] L.N. Zhang, Z.T. Hou, X. Ye, Z.B. Xu, X.L. Bai, P. Shang, Front. Mater. Sci. 7, 227 (2013) 
[6] J. Kubásek, D. Vojtěch, Trans. Nonferrous Met. Soc. China 23, 1215 (2013)

[7] X.B. Zhang, G.Y. Yuan, L. Mao, J.L. Niu, P.H. Fu, W.J. Ding. J. Mech. Behav. Biomed. Mater. 7, 77 (2012)

[8] V. Gärtnerová, Z. Trojanová, A. Jäger, P. Palček, J. Alloys Compd. 378, 180 (2004)

[9] P. Fu, L. Peng, H. Jiang, L. Ma, C. Zhai, Mater. Sci. Eng., A 496, 177 (2008)

[10] J. Kubásek, D. Dvorský, M. Čavojský, D. Vojtěch, N. Beronská, M. Fousová, J. Mater. Sci. Technol. 33, 652 (2017)

[11] N. Birbilis, M.A. Easton, A.D. Sudholz, S.M. Zhu, M.A. Gibson, Corros. Sci. 51, 683 (2009)

[12] C.Y. Su, D.J. Li, T. Ying, L.P. Zhou, L. Li, X.Q. Zeng, J. Alloys Compd. 685, 114 (2016)

[13] T.J. Pike, B. Noble, J. Less-Common Met. 30, 63 (1973)

[14] L. Ma, R.K. Mishra, M.P. Balogh, L.M. Peng, A.A. Luo, A.K. Sachdev, W.J. Ding, Mater. Sci. Eng., A 543, 12 (2012)

[15] J.F. Nie, B.C. Muddle, Acta Mater. 48, 1691 (2000)

[16] A. Sanaty-Zadeh, A.A. Luo, D.S. Stone, Acta Mater. 94, 294 (2015)

[17] B.N. Du, Z.Y. Hu, L.Y. Sheng, D.K. Xu, Y.F. Zheng, T.F. Xi, Acta Metall. Sin. (Engl. Lett.) 31, 351 (2018)

[18] P.H. Fu, L.M. Peng, H.Y. Jiang, J.W. Chang, C.Q. Zhai, Mater. Sci. Eng., A 486, 183 (2008)

[19] X.W. Zheng, J. Dong, Y.Z. Xiang, J.W. Chang, F.H. Wang, L. Jin, Y.X. Wang, W.J. Ding, Mater. Des. 31, 1417 (2010)

[20] H.Y. Yue, P.H. Fu, Z.M. Li, L.M. Peng, Mater. Sci. Eng., A 673, 458 (2016)

[21] Z.M. Li, A.A. Luo, Q.G. Wang, L.M. Peng, P.H. Fu, G.H. Wu, Mater. Sci. Eng., A 564, 450 (2013)

[22] L.M. Peng, P.H. Fu, Z.M. Li, H.Y. Yue, D.Y. Li, Y.X. Wang, Mater. Sci. Eng., A 611, 170 (2014)
[23] X.B. Zhang, Y.J. Xue, Z.Z. Wang, Trans. Nonferrous Met. Soc. China 22, 2343 (2012)

[24] J.L. Li, L.L. Tan, P. Wan, X.M. Yu, K. Yang, Mater. Sci. Eng., C 49, 422 (2015)

[25] L.B. Tong, M.Y. Zheng, L.R. Cheng, S. Kamado, H.J. Zhang, Mater. Sci. Eng., A 569, 48 (2013)

[26] L. Ma, R.K. Mishra, L.M. Peng, A.A. Luo, W.J. Ding, A.K. Sachdev, Mater. Sci. Eng., A 529, 151 (2011)

[27] X.B. Zhang, Z.Z. Wang, G.Y. Yuan, Y.J. Xue, Mater. Sci. Eng., B 177, 1113 (2012)

[28] D.L. Yin, J.T. Wang, J.Q. Liu, X. Zhao, J. Alloys Compd. 478, 789 (2009)

[29] Y.P. Wu, X.M. Zhang, Y.L. Deng, C.P. Tang, Y.Y. Zhong, J. Mater. Sci. Eng. A 644, 152 (2015)

[30] D.S. Gandel, M.A. Easton, M.A. Gibson, T. Abbott, N. Birbilis, Corros. Sci. 81, 27 (2014)

[31] J. Wang, L.G. Wang, S.K. Guan, S.J. Zhu, C.X. Ren, S.S. Hou, J. Mater. Sci. Mater. Med. 21, 2001 (2010)

[32] Q. Wu, S.J. Zhu, L.G. Wang, Q. Liu, G.C. Yue, J. Wang, S.K. Guan, J. Mech. Behav. Biomed. Mater. 8, 1 (2012)

[33] X.B. Zhang, G.Y. Yuan, Z.Z. Wang, Mater. Lett. 74, 128 (2012)

[34] P.A. Nuttall, T.J. Pike, B. Noble, Metallography 13, 3 (1980)

[35] N. Stanford, D. Atwell, A. Beer, C. Davies, M.R. Barnett, Scripta Mater. 59, 772 (2008)

[36] N. Stanford, M.R. Barnett, Mater. Sci. Eng., A 496, 399 (2008)

[37] N. Stanford, Mater. Sci. Eng., A 527, 2669 (2010)

[38] L.M. Peng, P.H Fu, Z.M. Li, Y.X. Wang, H.Y. Jiang. J. Mater. Sci. 49, 7105 (2014)

[39] Z.M. Li, P.H. Fu, L.M. Peng, Y.X. Wang, H.Y. Jiang, G.H. Wu, Mater. Sci. Eng., A 579, 170 (2013) 